\title{
Cervical Cancer, Papillomavirus, and miRNA Dysfunction
}

\author{
Evelyn Gabriela Bañuelos-Villegas, Maria Fernanda Pérez-yPérez and \\ Luis Marat Alvarez-Salas *
}

Laboratorio de Terapia Génica, Departamento de Genética y Biología Molecular, Centro de Investigación y de Estudios Avanzados Del I.P.N., México City, Mexico

Cervical cancer is the leading cause of death by cancer in women from developing countries. Persistent infection with high-risk human papillomavirus (HPV) types 16 and 18 is a major risk factor for cervical carcinogenesis. Nevertheless, only a few women with morphologic expression of HPV infection progress into invasive disease suggesting the involvement of other factors in cervical carcinogenesis. MicroRNAs (miRNAs) are conserved small non-coding RNAs that negatively regulate gene expression including genes involved in fundamental biological processes and human cancer. Dysregulation of miRNAs has been widely reported in cervical cancer. This work focuses on reviewing the

OPEN ACCESS

Edited by:

Guangchao $\mathrm{Li}$,

Guangzhou Bio-gene Technology Co.

Ltd, China

Reviewed by:

Lincan Duan,

Third Affiliated Hospital of Kunming Medical University, China

Guillermo Aquino-Jarquin,

Hospital Infantil de México Federico

Gómez, Mexico

*Correspondence:

Luis Marat Alvarez-Salas lalvarez@cinvestav.mx

Specialty section:

This article was submitted to RNA Networks and Biology,

a section of the journal

Frontiers in Molecular Biosciences

Received: 13 August 2021 Accepted: 18 November 2021 Published: 10 December 2021

Citation:

Bañuelos-Villegas EG,

Pérez-yPérez MF and

Alvarez-Salas LM (2021) Cervical

Cancer, Papillomavirus, and

miRNA Dysfunction.

Front. Mol. Biosci. 8:758337.

doi: 10.3389/fmolb.2021.758337
miRNAs affected during the HPV infection process, as well relevant miRNAs that contribute to the development and maintenance of malignant cervical tumor cells. Finally, we recapitulate on miRNAs that may be used to distinguish between healthy individuals from patients with precancerous lesions or cervical tumors.

Keywords: cervical cancer, human papillomavirus, HPV, miRNA, microRNA

\section{INTRODUCTION}

In 2020 there were 604,127 new cases and 341,831 deaths of women with cervical cancer worldwide (WHO, 2020). Clinically, cervical tumors can be classified as squamous cell carcinoma (SCC), corresponding to $70-80 \%$ of the cases, and adenocarcinoma (AC) with a $10-25 \%$ occurrence (Babion et al., 2020a). Other rare cervical tumors exhibit a variety of histological types including malignant adenoma, endometrioid carcinoma, clear cell carcinoma, papillary adenocarcinoma, adenoid cystic carcinoma, adenosquamous carcinoma, and undifferentiated carcinoma, which collectively represent less than $1 \%$ of the newly diagnosed cases (Berman and Schiller, 2017; Hull et al., 2020).

Infection with high-risk human papillomaviruses (HR-HPVs) is the primary risk factor for the development of cervical cancer (Castellsagué, 2008; $\mathrm{Li}$ and $\mathrm{Xu}$, 2017). Through the expression of two oncogenic viral proteins E6 and E7, HR-HPVs are capable of orchestrating diverse molecular mechanisms that may result in progression to malignant disease. Although persistent infection by HR-HPVs is a necessary cause of cervical cancer, only a few women with morphologic expression of HPV infection progress to invasive disease (Castellsagué, 2008). Hence, other tumor promoter factors must be involved. The identification of such factors is crucial for early diagnosis and could be useful for more efficient treatment and prognosis of cervical cancer.

Most studies generally focus on the genetic dysregulation of host-cell proteins associated with promoting cervical carcinogenesis. In recent years, research turned towards non-coding RNAs (ncRNAs), especially microRNAs (miRNAs). The miRNAs are highly-conserved small doublestranded ncRNAs 19 to 24 nucleotides long that negatively regulate the expression of coding genes through hybridization with complementary or near-complementary sequences within the $3^{\prime}$-UTR of 
target mRNAs (Felekkis et al., 2010; Bhaskaran and Mohan, 2014). Such binding specifically blocks translation or enables mRNA degradation (He and Hannon, 2004). Because of their functions, miRNAs are essential regulators of many biological pathways associated with cancer development.

\section{HPV Infection and Cervical Cancer}

HPVs are non-enveloped double-stranded DNA (dsDNA) viruses belonging to the Papillomaviridae family (Yuan et al., 2021). Most HPVs infect cells from the basal epithelium and have been classified into cutaneous or mucosal types (Burd, 2003). HPV viral particles are relatively small (approximately $60 \mathrm{~nm}$ ), consisting of an icosahedral capsid containing a single molecule of circular dsDNA of 8,000 base pairs (Harden and Munger, 2017). In general, the HPV genomes encode for six early (E1, E2, E4, E5, E6, and E7) and two late proteins (L1 and L2) (Bansal et al., 2016). There is a third non-coding region in the HPV genome known as the Long Control Region (LCR) or Upstream Regulatory Region (URR) containing the origin of DNA replication as well as transcription control sequences (Harden and Munger, 2017).

The early genes encode for proteins needed for viral replication and transcription. E1 is a DNA helicase essential for the viral replication and E2 works as a regulatory protein modulating the expression of E6 and E7 and regulating viral transcription, replication and genome partitioning (Ryndock and Meyers, 2014). E4 is embedded within the E2 gene and promotes the viral escape from the cornified epithelial layers by attaching to cytokeratin filaments, disrupting their structure (Harden and Munger, 2017). The E5 protein enhances proliferation and may contribute to cancer progression through controlling trafficking of proteins and the vacuolar ATPase in endosomes to modulate epidermal growth factor receptor turnover, thus maintaining a constitutive proliferative signaling (Moody and Laimins, 2010). The E6 and E7 proteins are the principal viral transforming factors. E6 binds and degrades p53 and cellular PDZ proteins and activates telomerase activity thus inhibiting the host cell p53-mediated apoptosis and senescence while E7 binds and degrades the retinoblastoma protein ( $\mathrm{pRB}$ ) leading to continuous cell-cycle rounds contributing to malignant progression by inducing genomic instability and abnormal and sustained host cell proliferation (Harden and Munger, 2017).

The viral late region encodes for the structural proteins L1 and L2. L1 is the major component of the virion capsid produced at the upper layer of the differentiated cervical epithelium during infection and is necessary for binding of the viral primary receptor heparan sulfate (HS). L2 is the minor capsid protein and is involved in the entrance of the viral genome into the host cell (Szymonowicz and Chen, 2020).

There are approximately 30-40 HPV types that infect the anogenital tract (Yuan et al., 2021). Depending on the association with cancer and precursor lesions, the HPV types were grouped in two main classifications: high risk (HR-HPVs) and low risk types (LR-HPVs). HR-HPVs types 16, 18, 31, 33, 35, 39, 45, 51, 52, 56, 58,59 , and 68 are commonly found integrated to the host cell genome in cervical tumor cells. Notably, most cervical tumors contain HPV16 or HPV18 which contribute to $\sim 70 \%$ of invasive cervical carcinoma cases globally (Bhatla and Singhal, 2020). HPV strains 6, 11, 40, 42, 43, 44, 54, 61, and 72 are considered as low-risk HPVs (LR-HPVs), often associated with benign anogenital warts and laryngeal papilloma (Okunade, 2020). It is presently unclear whether HPV types 53, 66, 70, 73 MM9, and 82 MM4 belong to high or low-risk classification.

Remarkably, about $80 \%$ of people will get an HPV infection at some point in their lives and usually become infected with HPV shortly after the onset of sexual activity. However, over $90 \%$ of those infected will spontaneously clear the infection within 9-12 months suggesting an active participation of the immune system in HPV infection (Szymonowicz and Chen, 2020).

Persistent infection by HR-HPVs can lead to benign Squamous Intraepithelial Lesions (SIL) (Figure 1). These lesions are classified as Low-grade Squamous Intraepithelial Lesions (LSIL) encompassing HPV infection or mild dysplasia also known as CIN1 (cervical intraepithelial neoplasia grade 1) and High-grade Squamous Intraepithelial Lesions (HSIL) encompassing moderate (CIN grade 2) and severe dysplasia (CIN grade 3 ). In CIN1 the abnormal proliferative cells are present only in the lower one-third of the epithelium. CIN2 and CIN3 are characterized by the expansion of the neoplasia to the lower two-thirds (CIN2) or more (CIN3) of the epithelium. Sometimes, CIN3 involves the full thickness of the epithelium, and it is also known as in situ cervical carcinoma (ISCC). HSILs are developed in $10-20 \%$ of women with LSILs, and less than $30 \%$ of the ISCC patients may progress to cervical tumors when the neoplasia invades into the stroma underneath (Wang et al., 2014; Shen et al., 2020).

Starting with an HPV infection, the transformation of normal cervical tissue to invasive cervical cancer (ICC) is a multistep process that implicates the sustained action of the oncogenic viral proteins E6 and E7 (Wang et al., 2018). Thus, E6 and E7 promote the transformation of normal cervical keratinocytes into premalignant and LSIL states and then to an HSIL with a subsequent transformation to ICC.

\section{miRNAs and Cancer}

Most miRNAs are involved in the regulation of fundamental biological processes, such as proliferation (Lenkala et al., 2014), differentiation (Yao, 2016), inflammation (Zhou W. et al., 2018), apoptosis (Taghavipour et al., 2020), cell cycle (Mens and Ghanbari, 2018), and immune response (Chandan et al., 2020). Due to their wide range of functions, miRNA dysregulation has significant consequences in terms of cellular outcomes enhancing the development of a wide range of diseases, including cardiovascular diseases (Zhou S.-S. et al., 2018), neurological disorders (Hussein and Magdy, 2021), autoimmune disorders (Salvi et al., 2019) and cancer (Peng and Croce, 2016).

In the specific case of cancer, it is well established that miRNA dysregulation plays a pivotal role in the initiation, progression, and dissemination of tumorigenesis. The miRNAs are capable of influencing the main features of the carcinogenic process such as continued proliferative capacity, apoptosis resistance, invasion and metastasis induction, increased angiogenesis and the evasion of growth inhibitor signals (Peng and Croce, 2016). 


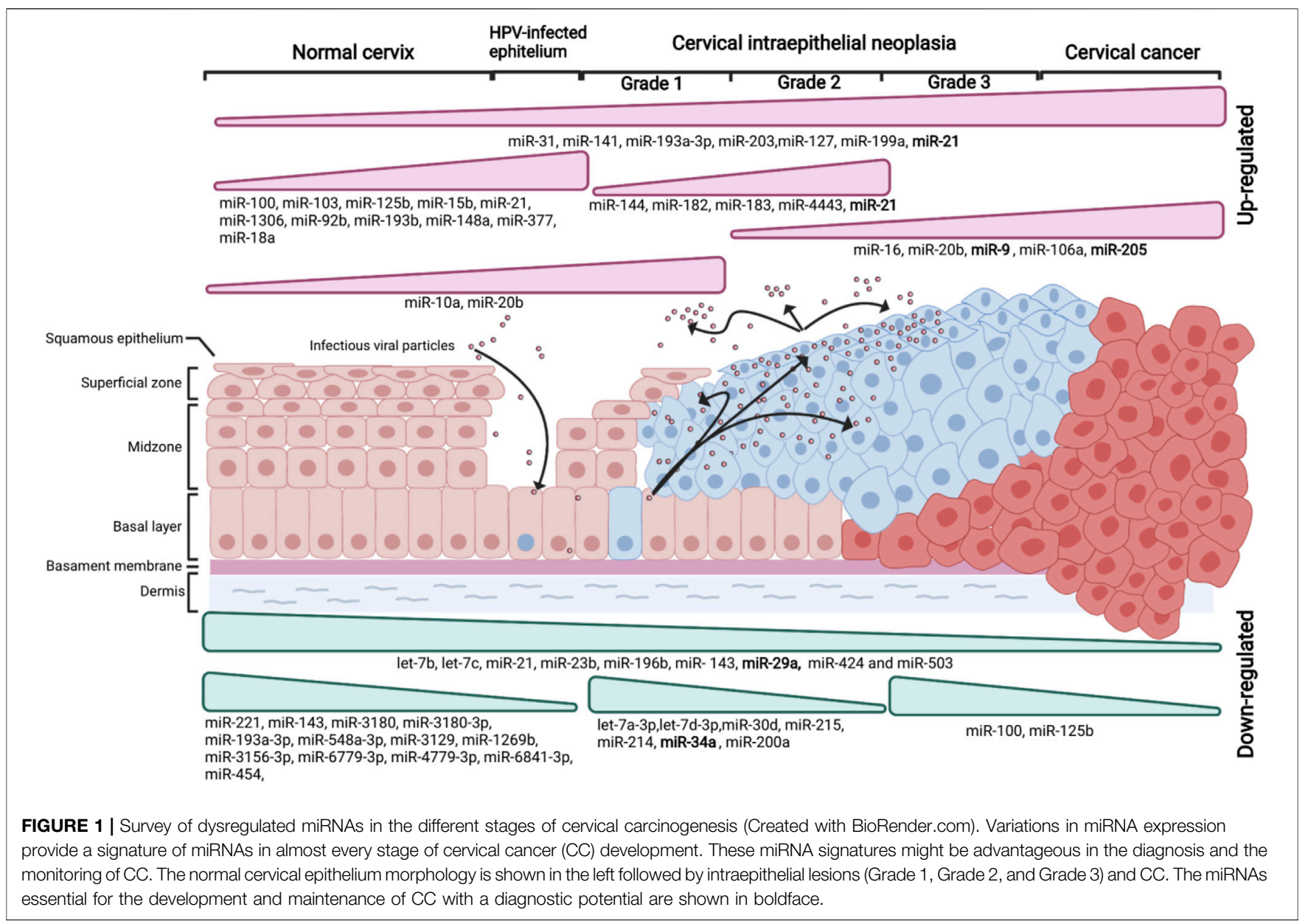

In several tumor types, miRNAs function by targeting transcripts from tumor suppressors or proto-oncogenes (Wang et al., 2008). Thus, miRNAs are subdivided into oncogenic miRNAs (oncomiRs) and tumor suppressor miRNAs (tsmiRs), respectively (Svoronos et al., 2016). OncomiRs are usually highly expressed promoting tumor progression and maintaining the tumor phenotype. On the other hand, the tsmiRs inhibit tumorigenesis by regulating cell proliferation, invasion, promoting apoptosis, and other processes related to cancer development. These tsmiRs are frequently downregulated in most human cancers (Ali Syeda et al., 2020).

The established connection between miRNAs and cancer is deeply associated with aberrant miRNA expression in different cancer types. The miRNA profile in any tumor type can provide various applications such as therapeutic targets or as diagnostic and prognostic markers. However, for the miRNAs to be used for diagnosis or therapy, there is a need for the understanding of their oncogenic or tumor-suppressive roles and how their dysregulation affects tumor progression. OncomiRs may play a meaningful role in cancer treatment through intervening with their expression by silencing or modulation, while the directed overexpression of tsmiRs may exhibit therapeutic effects.

In the specific case of ICC, several OncomiRs have been described, such as miR-499, which promotes cervical tumor progression by enhancing proliferation, migration, invasion, and apoptosis resistance via tumor suppressor SOX6 targeting (Chen Y. et al., 2020). Another example is miR-18a which is involved in the oncogenic transformation of $\mathrm{HPV}^{+}$cervical cells. A study found that HPV E6 and E7 increased the expression of miR-18a (Morgan et al., 2020). This overexpression leads in turn to higher proliferation, migration, and invasion via silencing of tumor-suppressive Hippo pathway STK4 mRNA.

MiR-125 is a well-known tsmiR in cervical cancer. Several authors established that miR-125 inhibited cervical cancer progression by targeting VEGF, thus inhibiting migration and invasion of cervical cancer cells (Fu et al., 2020). Also, miR-375 exerts tumor suppressor effects in cervical tumors via MELK downregulation, thus promoting cell apoptosis while impairing the proliferation, migration, and invasion (Ding et al., 2020).

Some miRNAs can play dual roles as OncomiRs and tsmiRs in cervical carcinogenesis. For example, miR-9-5p is upregulated in the HPV $16^{+} \mathrm{CaSki}$ and $\mathrm{SiHa}$ tumor cell lines originating from a SCC. In SCC, miR-9-5p plays an oncogenic role by generating downregulation of TWIST1 and CDH1, thus enhancing EMT induction. However, miR-9-5p expression is low in the HPV $18^{+}$ cervical AC cell line HeLa. In this scenario, TWIST is not repressed, so $\mathrm{CDH} 2$ activation might be necessary to maintain a malignant phenotype in cervical AC (Babion et al., 2020a). 


\section{HPV and miRNAs}

During infection, viruses play a significant role in regulating host gene expression. Part of the gene regulation mediated by viruses is due to changes in miRNA expression triggered by infection (Girardi et al., 2018). Persistent HPV infection induces abnormal miRNA expression (Zheng and Wang, 2011), which could trigger the transformation processes observed from HPV infection to cervical cancer.

Many researchers have studied the miRNA expression profile related to HPV infection and the development of cervical cancer. In 2020 Babion et al. using microarrays determined the miRNA expression profile associated with HPV infection in eight different passages of HPV-transformed keratinocytes representing different stages of cell transformation induced by HPV infection. In total, 106 mature miRNAs were found differentially expressed through the different cell passages. The most representative miRNAs validated by RT-qPCR were miR15b-5p, miR-100-5p, miR-103a-3p, miR-125b-5p, found upregulated and only miR-221-5p presented downregulation (Babion et al., 2020b).

Another study correlated the severity of the intraepithelial lesions from women infected with HPV-16 to the expression of a set of four miRNAs. The comparison between HPV $16^{+}$LSIL and cervical cancer patients showed an increased expression of miR16, miR-21, miR-34a, and miR-143 relative to the HPV-negative group. In the case of HSIL patients, miR-16 and miR-34a expression changes resulted irrelevant compared to the HPVnegative control group. However, miR-21 expression significantly increased while miR-143 decreased compared to the HPVnegative group (Norouzi et al., 2021).

Nunvar et al. identified dysregulated miRNAs exclusive for HPV-dependent SCC. The authors evaluated miRNA expression profiles in a group of $\mathrm{HPV}^{+}$anogenital tumors by next-generation sequencing (NGS). The set included cervical, vulvar, anal, and tonsillar tumors. A variation among tumor types on the total number of dysregulated miRNAs was observed. However, the highest number of miRNAs differentially expressed was detected in cervical $\mathrm{HPV}^{+}$tumors compared to the other SCCs. They also found more downregulated than upregulated miRNAs in $\mathrm{HPV}^{+}$ cervical tumors (Nunvar et al., 2021).

In a separate report, Tong et al. identified a subset of miRNAs associated with HPV status. They performed small RNA-seq in cervical tumor lines (2 $\mathrm{HPV}$-negative and $5 \mathrm{HPV}^{+}$) and the exosomes (EXOs) secreted by these cell lines. Specifically, EXOs presented a total of 32 miRNAs differentially expressed in HPV-positive relative to HPV-negative cell lines. The five most commonly upregulated were miR-92b-5p, miR-92b-3p, miR193a-5p, miR-193b-5p, and miR-1306-5p, while downregulation was reported for miR-548a-3p, miR-1269b, miR-3129-5p, miR-3180-5p, and miR-3180-3p. In tumor cell lines, 70 miRNAs were found differentially expressed in HPVpositive cells including miR-34a-5p, miR-199b-5p, miR-193a-3p, miR-193a-5p, and miR-365b-5p. Meanwhile, miR-431-5p, miR432-5p, miR-816a-5p, miR-3180-5p, and miR-3180-3p were observed downregulated in $\mathrm{HPV}^{+}$relative to $\mathrm{HPV}$-negative cells. Six miRNAs (miR-146-5p, miR-193a-5p, miR-4661-5p, miR-410-3p, miR-3180-5p and miR-3180-3p) were associated with HPV status in both EXOs and cells (Tong et al., 2020). All these findings suggest a potential miRNA expression deregulation associated with HPV-mediated cervical carcinogenesis.

Dysregulated miRNA expression in HPV infection is widely associated with the viral oncoproteins E5, E6, and E7. Downregulation of miR-454-5p, miR-656-5p miR-3156-3p, miR-4779-3p, miR-6779-3p and miR-6841-3p, was observed by microarrays from HPV-negative HT-3 cells ectopically expressing HPV16 E6 and E7. Further validation with RTqPCR in HT-3 and C33-A (HPV-negative) cells transfected with HPV16-E6/E7 showed a decrease in miR-3156-3p expression in both cell types. A reduction of miR-3156-3p in HPV16/18-positive cervical tumor samples were also reported. These findings indicate that $\mathrm{miR}-3156-3 \mathrm{p}$ expression is associated with HR-HPV infection and the HR-HPV oncoproteins (Xia et al., 2017).

Silencing of E5, E6, and E7 oncoproteins in the HPV $16^{+}$ cervical tumor lines CaSki and SiHa showed that the loss of the viral oncoproteins upregulates miR-148a-3p. Silencing of only E6 and E7 in SiHa cells showed an increased expression of miR199b-5p and miR-190a-5p. Overexpression of miR-190a-5p was observed by silencing E5 alone in CaSki. Thus, these three miRNAs might be used as biomarkers for the diagnosis of cervical cancer in HR-HPV-infected patients (Han et al., 2018). Additionally, in a cervical tumor microvesicles (CCMVs) study, HeLa cells transfected with siRNAs against HPV18 E6/E7 showing increased expression of miR-377. These findings suggested that miR-377 may play a role in E6/ E7-mediated oncogenesis (Zhang et al., 2020).

Morgan et al. evaluated the role of HPV16 and 18 E6/E7 oncoproteins in the transformation of HeLa (HPV-18) and CaSki (HPV-16) cells. Upregulation of miR-18a was observed after silencing E6/E7. MiR-18a directly targets the STK4 3'-UTR, a tumor suppressor gene that correlates with the Hippo pathway involved in the hyperproliferative state of the tumor cells (Morgan et al., 2020).

\section{HPV-Coded miRNAs in Cervical Cancer}

There is little evidence that HPV is capable of coding its own viral miRNAs. A bioinformatic study predicted novel putative HPV pre-miRNAs among different HPV types. Surprisingly, HPV16 showed the coding potential for three unique pre-miRNAs HPV16-miR-1, HPV16-miR-2, and HPV16-miR-3 located at E6, E1, and L2 ORFs, respectively. Using the miRTar tool, the putative target genes for HPV16-miR-1 were predicted as ARID5B, ZEB2, THBS1, genes involved in cell motility and migration, and STAT5B related to cell adhesion. For HPV16miR-3, the predicted targets were SYNE1, PDE1B, GATA6, and GULP1 associated with cell death. However, the predicted targets for HPV16-miR-2 (AFF3, FRMD7, IGDCC4, MYRIP, NRN1, PMP22, RBPMS) were not associated with cervical cancer progression. With this approach, the authors suggested that viral miRNAs might facilitate the host immune response evasion through advocating the latent phase of the HPV life cycle, thus increasing the risk for cancer development although no experimental evidence of these viral miRNAs has been provided so far (Weng et al., 2017). 
Although it appears that viral miRNAs could play a significant role in HPV infection and cervical cancer development, there is a controversy about the existence and possible function of these putative viral miRNAs. Accordingly, further research is required to establish if HPV is indeed capable to express its miRNAs and define their functions for the diagnosis, prognosis, or therapy against cervical cancer.

\section{Dysregulation of miRNAs in cervical cancer}

Most miRNAs are encoded as individual genes or gathered in clusters along with other miRNAs and either expressed from their own promoters or as passenger transcripts within introns (Cai et al., 2009). Canonical miRNA biogenesis is a stringently regulated process starting with a primary transcript (primiRNA) produced by RNApolII transcription containing $5^{\prime}$ cap and $3^{\prime}$ polyA tail ( $\mathrm{Ha}$ and Kim, 2014).The pri-miRNA structures as a defined stem-loop determined by internal basepairing and is processed in a structure-driven manner within the nucleus by the Microprocessor complex, containing the RNAse III-like enzyme Drosha and the RNA binding protein DGCR8, that cleaves the base of the stem generating a 2 nt overhang at the 3 ' end. The resulting precursor miRNA (pre-miRNA) retains the stem-loop structure and is exported to the cytoplasm by the Exportin 5/Ran-GTP complex (Gregory et al., 2004). There, a cytoplasmic RNAse III-like enzyme, Dicer, cuts out the loop leaving a $21 \mathrm{nt}$ double-stranded miRNA molecule. The miRNA is bound by an RNA-induced silencing complex (RISC) composed of TRBP, Dicer and AGO2 in humans (Chendrimada et al., 2005) and one of the strands is used as guide sequence to mediate sequence-dependent silencing of complementary target mRNAs (Lai, 2002). Therefore, mutations on the miRNA promoters, sequence, biogenesis regulatory regions or target sites and alterations on the miRNA biogenesis proteins may cause dysregulation, loss of specificity or even silencing of the miRNA function with deleterious consequences for the cell.

Numerous researchers have characterized some of the mechanisms causing miRNA dysregulation and their expression pattern in cervical cancer. Compelling evidence suggests that alterations in miRNA expression might result from genomic variations of miRNA genomic loci, such as genetic deletions, amplifications, or mutations. For example, 45 deregulated miRNAs were identified in advanced SCC cells associated with high expression of Drosha and a gain of chromosome 5p. These 45 miRNAs include miR-31, miR-141, miR-203 upregulated, and miR-193a-3p downregulated in clinical samples. Additionally, a majority of miRNAs upregulated were identified in Drosha-overexpressing cells, with only five being down-regulated (Muralidhar et al., 2011).

It is well-known that alteration of transcriptional activators and repressors and abnormal DNA methylation modification of miRNA genomic loci often causes an aberrant miRNA expression profile in cancer (Hussen et al., 2021). In addition to the genomic alterations and patterns of methylation of the miRNA gene sequence, dysregulation of the proteins implicated the miRNA biogenesis contributes to the alterations of miRNA expression in cervical cancer (Ali Syeda et al., 2020).
Another factor that modifies miRNA expression in cervical tumors is single nucleotide polymorphisms (SNPs). SNPs within miRNA genes alter their maturation process by destabilizing the miRNA precursor secondary structure, interfering with Drosha and Dicer processing and strand choice (Wang Y. et al., 2021). Therefore, SNPs in miRNAs deregulate their expression, thus affecting the binding to their target genes. These alterations are well associated with cancer development. Zhi, et al. explored the association between the SNPs in miR-21, miR-26b, miR-221/222, and miR-126 in healthy, CIN, and CC patients. The authors showed that rs1292037 in miR-21 might be involved in the development of CIN or CC. In the case of miR-126, they found that rs2297538 and rs2297537 SNPs might be implicated in the progression of CIN to cervical carcinoma. Finally, the SNP rs2745709 in miR-221/222 might be associated with the development of a CIN lesion (Yang et al., 2021).

Furthermore, a case-control study in the Chinese population evaluated the influence of SNPs in the promoter of the miR-17-92 cluster (miR-17, miR-18a, miR19a, miR-19b, miR-20a, and miR92-1) in the development of SCC. The authors found a lower level of oncogene miR-20a in patients with the rs9588884GG genotype. Since miR-20a promotes the proliferation, migration, invasion, and suppression of apoptosis of cervical carcinoma cells, the rs9588884 GG genotype seemingly reduces the risk of SCC (Huang et al., 2020). Another case-control study carried out by the same authors found that miR-34b/c rs4938723 $\mathrm{C} / \mathrm{T}$ polymorphism is also associated with cervical cancer risk in the Chinese population (Yuan et al., 2016). Liu et al. associated the downregulation of let-7i with a higher risk of cancer development by the presence of SNPs in the let-7i promoter (Liu and Ni, 2018).

Infection with HR-HPV causes alterations in miRNA expression which are essential to maintain a transformed phenotype and subsequent progress to invasive carcinoma. Different studies evaluated miRNAs expression in a range of cell lines, biopsies, cervical mucus, exfoliated cervical cells, and serum from women diagnosed with SCC. These studies showed highly variable miRNA expression during the different stages of cervical cancer.

Lui et al. by direct sequencing found downregulation of miR196b, miR-23b, miR-143, let-7b, let-7c, and an upregulation of miR-21 in cervical carcinoma cells compared with nontumorigenic cervical samples (Lui et al., 2007). In a different report, miR-127 and miR-199a were found upregulated in invasive SCC compared with non-tumorigenic cervical squamous epithelial samples. The upregulation of miR-127 was associated with lymph node metastasis. Likewise, miR-199 promoted tumorigenesis by enhancing cell growth (Lee et al., 2008).

Variations in miRNA expression also have been reported during the transition from LSIL to HSIL and invasive CC. Zheng et al. described eight differentially secreted exosomal miRNAs; miR-30d-5p, let-7a-3p, let-7d-3p, miR-215-5p downregulated, and miR-144-5p, miR-182-5p, miR-183-5p, miR-4443 upregulated between patients presenting HSILs from those with LSILs. The same study identified miR-30d-5p and let- 
TABLE 1 | Differential expression of miRNAs in cervical carcinogenesis. CIN, cervical intraepithelial neoplasia; SCC, squamous cervical carcinoma

\begin{tabular}{|c|c|c|c|}
\hline & $\begin{array}{l}\text { Differential } \\
\text { expression }\end{array}$ & miRNAs & References \\
\hline \multicolumn{4}{|c|}{ HPV infection } \\
\hline \multirow[t]{3}{*}{$\begin{array}{l}\text { VPH infected cells vs } \\
\text { normal cervical cells }\end{array}$} & Upregulated & $\begin{array}{l}\text { miR-100-5p, miR-103a-3p, miR-125b-5p, miR-15b-5p, miR-143- } \\
\text { 5p, miR-1306-5p, miR-92b-5p, miR-92b-3p, miR-193a-5p, and } \\
\text { miR-193b-5p }\end{array}$ & $\begin{array}{l}\text { Babion et al. (2020b); Norouzi et al. (2021); } \\
\text { Tong et al. (2020) }\end{array}$ \\
\hline & Downregulated & $\begin{array}{l}\text { miR-221-5p, miR-3180-5p, miR-3180-3p, miR-548a-3p, miR- } \\
3129-5 p \text { and miR-1269b, miR-432-5p, miR-816a-5p, miR-431- } \\
\text { 5p, miR-3156-3p, miR-148a-3p }\end{array}$ & $\begin{array}{l}\text { Babion et al. (2020b); Tong et al. (2020); Xia } \\
\text { et al. (2017); Zhang et al. (2020) }\end{array}$ \\
\hline & \multicolumn{3}{|c|}{ Cervical intraepithelial neoplasia } \\
\hline \multirow[t]{2}{*}{ CIN2/3 vs CIN1 } & Upregulated & $\begin{array}{l}\text { miR-21, miR-144-5p, miR-182-5p, miR-183-5p, miR-4443, } \\
\text { miR-10a }\end{array}$ & $\begin{array}{l}\text { Wang et al. (2019); Pardini et al. (2018); } \\
\text { Norouzi et al. (2021) }\end{array}$ \\
\hline & Downregulated & $\begin{array}{l}\text { let-7a-3p, let-7d-3p, miR-30d-5p, miR-215-5p, miR-214, miR- } \\
34 a, \text { miR-200a, miR-143 }\end{array}$ & $\begin{array}{l}\text { Zheng et al. (2019); (Wang et al. (2019); } \\
\text { (Norouzi et al. (2021) }\end{array}$ \\
\hline \multirow[t]{3}{*}{ CIN2/3 vs normal samples } & Upregulated & miR-125a, miR-21 & $\begin{array}{l}\text { Wang et al. (2019); Bayramoglu Tepe et al. } \\
\text { (2021) }\end{array}$ \\
\hline & Downregulated & $\begin{array}{l}\text { miR-30e, miR-96, miR-30a, miR-130a, miR-302a, miR-143, miR- } \\
\text { 372, miR-17, miR-375, miR-30c, miR-520e, miR-548c, miR-373, } \\
\text { miR-214, miR-34a and miR-200a }\end{array}$ & $\begin{array}{l}\text { Wang et al. (2019); Bayramoglu Tepe et al. } \\
\text { (2021) }\end{array}$ \\
\hline & \multicolumn{2}{|r|}{ Cervical cancer } & \\
\hline \multirow{4}{*}{$\begin{array}{l}\text { SCC vs normal cervical } \\
\text { samples } \\
\text { SCC vs CIN1 }\end{array}$} & Upregulated & miR-21, miR-127 and miR-199a & Lui et al. (2007); Lee et al., (2008) \\
\hline & Downregulated & let-7b, let-7c, miR-23b, miR-196b, miR-143 & Lui et al. (2007) \\
\hline & Upregulated & $\begin{array}{l}\text { miR-96-5p, miR-17-5p, miR-130a-5p and miR-520b-5p miR-16- } \\
\text { 5p, miR-20b-5p, miR-9-5p, miR-106a-5p, miR-205-5p }\end{array}$ & $\begin{array}{l}\text { Bayramoglu Tepe et al. (2021); Pardini et al. } \\
\text { (2018); Norouzi et al. (2021) }\end{array}$ \\
\hline & Dowregulated & $\begin{array}{l}\text { miR-30e-5p, miR-30a-5p and miR-30c-5p, miR-143-5p, miR- } \\
372-5 p \text {, miR-375-5p, miR-520e-5p }\end{array}$ & $\begin{array}{l}\text { Bayramoglu Tepe et al. (2021); Norouzi et al. } \\
\text { (2021) }\end{array}$ \\
\hline
\end{tabular}

$7 \mathrm{~d}-3 \mathrm{p}$ as strong predictors for clinical diagnosis due to the highly differential expression between patients with CIN1 and CIN2 (Zheng et al., 2019). Moreover, Wang et al. found that overexpression of miR-21 and downregulation of miR-214, miR-34a, and miR-200a expression in plasma is associated with the severity of the cervical lesion. Expression of these miRNAs in HSILs was significantly different from those patients with lower-grade lesions (Wang et al., 2019).

Using a bioinformatics approach, Dai et al. identified the downregulation of KFL4 and ESR1 closely related to poor prognosis triggered by the high expression of miR-21 and miR-16 in CC (Dai et al., 2019). Likewise, a systematic study by Pardini et al. identified miR-29a downregulation and miR-21 upregulation. The same study found miR-10a, miR-9, miR-20b, miR-106, and miR-16 as frequently CC dysregulated miRNAs (Pardini et al., 2018).

Downregulation of miR-188 and upregulation of miR-223 is linked with short survival of cervical cancer patients, while downregulation of miR-125b and miR-99a was associated with the 5-years survival rate (Gao et al., 2018). Qi et al. by bioinformatics assays validated the signature of a set of miRNAs correlated to cancer prognosis (miR-585-5p, miR216b-5p, and miR-7641) and validate these miRNAs through in vitro assays (Qi et al., 2020). Moreover, it was established that miR-503 and miR-424 are expressed as a cluster and it was downregulated in CC cells. Upregulation of miR-424/miR-503 impaired cell proliferation, epithelial-mesenchymal transition (EMT), migration, and invasiveness, but improve autophagy (Chen X. et al., 2020).

Tepe et al., explore the potential diagnosis and prognosis of miRNAs involved in autophagy. To achieve this goal, they evaluate the expression of such miRNAs in SCC, founding miR-30e-5p, miR-30a-5p and miR-30c-5p, miR-143-5p, miR372-5p, miR-375-5p, miR-520e-5p downregulated in the SCC samples compared with HSILs, whereas miR-96-5p, miR-17-5p, miR-130a-5p and miR-520b-5p were upregulated. Finally, they identified miR-30a-5p, miR-520e-5p, miR-548c-5p and miR-372$5 \mathrm{p}$ as significant diagnostics markers for SCC, due to the significant association of this miRNAs with the overall survival of SCC patients (Bayramoglu Tepe et al., 2021).

\section{MiRNAs, in development, progression, and maintenance of cervical cancer}

As shown above, miRNA dysregulation may play a significant role in the onset and progression of cervical cancer. Nevertheless, every study appears to suggest different miRNAs associated with the initiation and progression of cervical cancer (Table 1). For clarity, we enlisted the most frequently dysregulated miRNAs in the different stages of cervical cancer progression and their effect on cellular pathways (Table 2).

\section{MiR-9-5p}

In humans, miR-9 is coded by three different genes (miR-9-1, miR9-2, and miR-9-3) located at different chromosomes: 1q22, 5q14.3, and $15 \mathrm{q} 26.1$, respectively. The presence of miR-9 sequences in three different loci coupled with the high level of sequence conservation, suggests an important role of this miRNA on the cell cycle and the development of cancer (Nowek et al., 2018).

Expression of miR-9 is upregulated in HPV16-infected LSIL compared with the HPV- negative healthy population, while is significantly reduced in HPV52 and HPV58-infected dysplasia 
TABLE 2 | Relevant target genes for dysregulated miRNAs in cervical cancer.

\begin{tabular}{|c|c|c|c|c|c|}
\hline miRNA & Clasification & Target & Pathway & Associated events & Reference \\
\hline $\operatorname{miR}-9-5 p$ & OncomiR & $\mathrm{CDH} 1$ & Angiogenesis & $\begin{array}{l}\text { Down-regulation of } \mathrm{CDH} 1 \text { leads to activation of } \beta \text {-catenin, resulting } \\
\text { in the up-regulation of VEGFA, a proangiogenic factor }\end{array}$ & $\begin{array}{l}\text { Farzanehpour et al. } \\
\text { (2019) }\end{array}$ \\
\hline $\operatorname{miR}-9-5 p$ & OncomiR & TWIST1 & Metastasis & $\begin{array}{l}\text { Suppression of epithelial protein } \mathrm{CDH} 1 \text { and transcriptional } \\
\text { activation of mesenchymal marker } \mathrm{CDH} 2\end{array}$ & Babion et al. (2020a) \\
\hline miR-9-5p & OncomiR & SOC5/ & $\begin{array}{l}\text { Angiogenesis/ } \\
\text { Radiosensitivity }\end{array}$ & Increasing EMT transition and tube formation & Wei et al. (2019) \\
\hline miR-21-5p & OncomiR & PDCD4 & Immune evasion & $\begin{array}{l}\text { Down-regulation of PDC4 resulting in suppression of the } \\
\text { inflammation process via NF-kB activating the anti-inflammatory } \\
\text { cytokine interleukin } 10\end{array}$ & Asangani et al. (2008) \\
\hline miR-21-5p & OncomiR & PTEN & Tumorigenesis & $\begin{array}{l}\text { PTEN down-regulation amplifies PI3K signaling resulting in } \\
\text { sustaining proliferative signaling }\end{array}$ & Bumrungthai et al. (2015) \\
\hline miR-34a-5p & TsmiR & WNT1 & Proliferation/Invasion & $\begin{array}{l}\text { Induction of an E-P cadherin switch via the WNT1/ } \beta \text {-catenin } \\
\text { pathway }\end{array}$ & (Li et al. (2020)) \\
\hline miR-34c-3p & TsmiR & MAP2 & Proliferation & $\begin{array}{l}\text { Microtubule stabilization of MAP2 leads to proliferation inhibition } \\
\text { and cell death in tumor cells }\end{array}$ & $\begin{array}{l}\text { Córdova-Rivas et al. } \\
\text { (2019) }\end{array}$ \\
\hline miR-29a & TsmiR & STIR1 & $\begin{array}{l}\text { Migration and } \\
\text { invasion }\end{array}$ & $\begin{array}{l}\text { SIRT1 suppressed E-cadherin expression and promoted } \\
\mathrm{N} \text {-cadherin expression }\end{array}$ & Nan et al. (2019) \\
\hline $\mathrm{miR}-29 \mathrm{a}$ & TsmiR & HSP47 & Metastasis & $\begin{array}{l}\text { Overexpression of molecular chaperone HSP47 leads to cell } \\
\text { migration and invasion }\end{array}$ & (Yamamoto et al. (2013)) \\
\hline $\operatorname{miR}-16-1$ & OncomiR & CCNE1 & Cell cycle & Cyclin E1 (CCNE1) promotes transition of cells from G1 to S phase & $\begin{array}{l}\text { Zubillaga-Guerrero et al. } \\
(2015)\end{array}$ \\
\hline $\operatorname{miR}-148 b$ & TsmiR & CASP3 & Apoptosis & $\begin{array}{l}\text { Caspase- } 3 \text { activated death protease, catalyzing the specific } \\
\text { cleavage of many key cellular proteins }\end{array}$ & Mou et al. (2016) \\
\hline miR-182 & TsmiR & DNMT3a & Apoptosis & $\begin{array}{l}\text { Hypermethylation by DNMT3a resulted in the silencing of tumor } \\
\text { suppressor genes }\end{array}$ & Sun et al. (2015) \\
\hline miR-155-5p & OncomiR & TP53INP1 & Invasion & $\begin{array}{l}\text { TP53INP1 blocks tumor progression via p53-dependant and } \\
\text {-independent pathways }\end{array}$ & Li et al. (2019a) \\
\hline $\operatorname{miR}-452 b-5 p$ & OncomiR & $\begin{array}{l}\text { WTX, } \\
\beta \text {-Catenin }\end{array}$ & Invasion/Migration & $\begin{array}{l}\text { WTX, } \beta \text {-catenin, } \beta \text {-TrCP2, APC and AXIN1 form a complex that } \\
\text { could inhibit cancer progression by ubiquitination of } \beta \text {-catenin } \\
\text { protein }\end{array}$ & Li et al. (2019c) \\
\hline miR-204 & TsmiR & ATF2 & Autophagy & $\begin{array}{l}\text { Phosphorylated ATF2 bind to promoter region of genes involved in } \\
\text { cell cycle and autophagy }\end{array}$ & Li et al. (2019b) \\
\hline Let-7a & TsmiR & PKM2 & Invasion/Migration & $\begin{array}{l}\text { PKM2 in the role of protein kinase contribute to development of } \\
\text { tumorigenesis }\end{array}$ & Guo et al. (2017) \\
\hline
\end{tabular}

(Liu et al., 2020). These differences suggest that different HPVs may have different infection patterns, and thus the levels of key miRNAs may be differentially affected. This situation reflects the challenges faced by investigations aimed to find differences in the expression levels of miRNAs in cervical cancer, as the natural history of HPV infection is not yet fully understood and it is suspected that this may vary depending on the viral subtype, and that it is practically impossible to determine when the infection has started on a patient tested positive for HPV and how long the infection has been ongoing at the time of sampling (Woodman et al., 2007). Once normal tissue has progressed to HPVassociated dysplasia, it has been observed downregulation of miR-9, resulting in high levels of E-cadherin what leads to activation of $\beta$-catenin. The final result is the up-regulation of VEGFA, a proangiogenic factor (Pardini et al., 2018; Farzanehpour et al., 2019). Nevertheless, Babion et al. explored in more detail the role of miR-9 in the most common CC types (SCC and AC), finding that miR-9 expression is influenced by tumor histotype and by HR-HPV type. They found that miR-9$5 p$ could be acting like an oncomiR, by targeting TWIST1 and CDH1. In contrast, miR-9-5p acts as tsmiR in AC, since the EMT phenotype is achieved by low levels of miR-9-5p, which facilitated the upregulation of $\mathrm{CDH} 2$ via TWIST1 (Babion et al., 2020a).

\section{MiR-21-5p}

The locus for pri-miR-21 is found within the intronic region of the VMP1 gene located in chromosome 17 (Kumarswamy et al., 2011). MiR-21 is abundantly expressed in mammalian cells and its up-regulation is associated with many cancers.

Lui et al. reported the up-regulation of miR-21 expression in HPV-positive CC compared with that in LSILs, especially in HPV16-infected tumors. Conversely, in cervical tumors infected with HPV52 and HPV58, the miR-21 levels are not statistically different compared with LSILs infected with the same type. These results indicate that miR-21 dysregulation could be useful as a biomarker particularly in HPV16-infected tumors (Liu et al., 2020). Mir-21 targets several genes associated with cancer such as PTEN, PDCD4, RECK, and STAT3 (Asangani et al., 2008; Bumrungthai et al., 2015; Bautista-Sánchez et al., 2020). The role of miR-21 in CC was deepened by Bumrungthai et al. where miR-21 expression in HPV-negative normal cytology was significantly lower than in HPV-positive samples in abnormal tissue and SCC. This result demonstrates that induction of miR21 might be involved in HPV infection, and cervicitis (Bumrungthai et al., 2015). It has been proposed that the miR21 overexpression could lead to the down-regulation of PDC4 resulting in suppression of the inflammation process via NF-kB 
activating the anti-inflammatory cytokine interleukin 10, leading to immune evasion and cervical cancer progression (Asangani et al., 2008). MiR-21 can also control the PI3K/AKT/mTOR pathway by inhibiting AKT activation increasing NF-kB activity leading to inflammation.

\section{MiR-34a and miR-34c}

The miR-34 family consists of miR-34a, located on chromosome 1p36, miR-34b, and miR-34c co-transcribed from chromosome 11q23 (Navarro and Lieberman, 2015). MiR-34a is a classical tumor suppressor gene and is frequently down-regulated in gastric cancer, liver cancer, prostate cancer, and cervical cancer (Zhang et al., 2016). The study of miR-34a in cervical cancer began in 2009 when Wang et al. showed that cervical tumors and cervical cancer-derived cell lines containing oncogenic HPVs displayed reduced expression of tumorsuppressive miR-34a, attributed to the expression of the viral protein E6, which destabilizes the tumor suppressor p53, a known miR-34a transactivator (Wang et al., 2009). Later, Li et al. observed a reduced pri-miR-34a expression in cervical tumors and precancerous lesions. Such diminution could be detected in a very early stage, suggesting that miR-34a inhibition is induced by HR-HPV E6 oncoprotein through the 553 pathway, constitute an early-onset event in the development of CC (Li et al., 2010). The mechanism that has been proposed for miR-34 to promote the proliferation and invasion of cervical cells with SCC is through its target WNT1 by induction of an E-P cadherin switch via the WNT1/ $\beta$-catenin pathway (Li et al., 2020).

miR-34c is another miR-34 family member it's been associated with CC. Lopez et al. found an inhibitory proliferation effect of miR-34c-3p and miR-34c-5p in CC SiHa cells. Further, the authors establish that only miR-34c-3p is involved in, apoptosis, cell migration, and invasion. Thus, suggesting that miR-34c-3p and miR-34c-5p may target different mRNAs and thus harbor dissimilar functional roles (López and Alvarez-Salas, 2011). These results were complemented by Rivas et al., who demonstrated that miR-34c-3p mimic transfection led to the clear downregulation of MAP2 protein, as well as of MMP9 activity (Córdova-Rivas et al., 2019). Also found that 5p and 3p strands of miR-34 family members have differential effects in cell proliferation, migration, and invasion in cervical cancer cells, however, the mRNA targets regulated by $5 p$ and $3 p$ arms of miR34 family members are needed to clarify, and this could elucidate the differential effects of this miRNAs on cell processes.

\section{MiR-29a}

The miR-29 family consists of four members (miR-29a, miR129b-1, miR-29b-2, and miR-29c) encoded in two gene clusters. In humans, miR-29b-1 and miR-29a are located at chromosome 7, and miR-29b-2 and miR-29c are situated on chromosome 1 (Wang et al., 2015). It has been shown that miR-29a is downregulated in tumors and HPV-positive LSILs (Yamamoto et al., 2013; Jia et al., 2015; Servín-González et al., 2015). In 2019, Zamani et al. reported a significant decrease in miR-29 in tumor samples relative to the control groups, suggesting that miR-29a could operate as a tumor-suppressor in CC progression (Sara et al., 2019). MiR-29a participated in the migration, invasion, and
EMT directly targeting the $3^{\prime}$-UTR of SIRT1 mRNA (Nan et al., 2019). Recently it has been demonstrated that miR-29a regulates the p16 methylation pattern in CC by downregulating DNMT3A and DNMT3B (Wang A. et al., 2021). Also, it has been found that miR-29a regulates HSP47 having a key role in the maturation of collagen molecules. The diminution of HSP47 inhibited cancer cell migration and invasion, suggesting that the miR-29a-HSP47 pathway contributes to the metastasis of cervical SCC (Yamamoto et al., 2013).

\section{Role of miRNAs as biomarkers in early stages of cervical cancer}

Currently, histopathology and cytology (Pap-smear) are the gold standard for detection of HPV-associated dysplasia and cervical cancer. Although efficient and low-cost, these methods have a relatively low sensitivity (about 50\%) and heavily rely on interpretation, sample recollection and technician training (WHO, 2014). Recent updates in cervical cancer screening guidelines include the addition of HPV testing to cervical cytology, which provides $60-70 \%$ greater protection against ICC compared to Pap-smear alone (Bedell et al., 2020). Nevertheless, more sensitive approaches are needed for early and opportune diagnosis. In this regard, liquid biopsy-based approach may theoretically represent a valid additional (or alternative) model for CC screening, diagnosis, and follow-up (Palmirotta et al., 2018). In liquid biopsy, smalls non-coding RNAs gain a central role in cervical cancer diagnosis and prognosis, being major components in circulating RNA detection and exosome identification (Table 3). The need for markers that indicate the presence of cervical dysplasia in early stages is urgently required, as early stages of cervical carcinogenesis are usually asymptomatic, and in advanced cervical carcinoma the symptoms are general and shared with several conditions (Jia et al., 2015).

Because miRNAs are highly stable ncRNA species compared with mRNAs and some IncRNAs and have a relatively high average half-life ( 5 days on average), miRNAs can be considered as prognostic biomarkers of cervical cancer (Jiang et al., 2020). The potential clinical relevance of certain miRNAs in cervical tissue samples was explored by Park et al., demonstrating the potential to miR-21 and miR-155 combined with an HPV E6/E7 mRNA assay as biomarkers for diagnosis and management of both HPV positive and HPV negative LSILs and cervical tumors (Park et al., 2017). In a study conducted in Chinese population, miR-21 was notably upregulated and suggested as a biomarker to distinguish cervical tumors from LSILs. Another miRNA involved in the differentiation between LSILs and CC is miR34a, especially in HPV16 infected patients. (Liu et al., 2020).

Recently, Zamanni et al. explored the differences between the levels of miR-21 and miR-29a in $\mathrm{HPV}^{+}$and cervical tumor groups using liquid-based cytology samples (LBCs) in Iranian women. Both miR-21 and miR-29a can serve for cervical cancer diagnosis because of the existing correlation between miR-21 upregulation and the downregulation of miR-29a in tumor samples (Sara et al., 2020). Another study using LBCs showed the up-regulation of miR-205 in HSILs, suggesting the utility of miR-205 expression as 
TABLE 3 | Molecular models for early cervical cancer diagnosis and screening

\begin{tabular}{|c|c|c|c|}
\hline Method & Description & Role in cervical cancer diagnosis and prognosis & Reference \\
\hline $\begin{array}{l}\text { Circulating tumor cells } \\
\text { (CTCs) }\end{array}$ & $\begin{array}{l}\text { Isolation of tumor cells in bloodstream utilizing their physical } \\
\text { differences compared with leukocytes }\end{array}$ & $\begin{array}{l}\text { Identification and quantification of HPV oncogenes and epithelial } \\
\text { markers, by using molecular and/or immunofluorescence } \\
\text { procedures }\end{array}$ & $\begin{array}{l}\text { Palmirotta et al. } \\
\text { (2018) }\end{array}$ \\
\hline $\begin{array}{l}\text { Circulating Cell-Free } \\
\text { DNA (ctDNA) }\end{array}$ & $\begin{array}{l}\text { Detection of tumor DNA free in the circulatory system by } \\
\text { extremely sensitive detection methods }\end{array}$ & $\begin{array}{l}\text { Finding of distinctive mutated genes in cervical cancer or viral } \\
\text { DNA by NGS panels or dPCR. }\end{array}$ & $\begin{array}{l}\text { Palmirotta et al. } \\
(2018)\end{array}$ \\
\hline $\begin{array}{l}\text { Cell-Free Circulating } \\
\text { non-coding RNA }\end{array}$ & $\begin{array}{l}\text { Detection of tumoral ncRNAs in the bloodstream, active } \\
\text { release by cancer cells }\end{array}$ & $\begin{array}{l}\text { Searching for IncRNA or miRNA characteristic of CC taking } \\
\text { advantage of stability of ncRNAs in plasma compared with other } \\
\text { nucleic acid }\end{array}$ & $\begin{array}{l}\text { Cafforio et al. } \\
(2021)\end{array}$ \\
\hline Exosomal miRNAs & $\begin{array}{l}\text { Analysis of miRNAs shuttled in extracellular vesicles that } \\
\text { can be easily detected in body fluids thanks to their } \\
\text { abundance and stability }\end{array}$ & Identify signature DEmiRs in patients with CINs and CC. & $\begin{array}{l}\text { Cafforio et al. } \\
(2021)\end{array}$ \\
\hline $\begin{array}{l}\text { Detection of aberrant } \\
\text { methylation pattern }\end{array}$ & $\begin{array}{l}\text { Analysis of methylation pattern in cervical scraps or biopsy } \\
\text { in genes }\end{array}$ & $\begin{array}{l}\text { Detection of aberrant DNA methylation of oncogenes and ts- } \\
\text { genes using affinity capture of methylated DNA. }\end{array}$ & $\begin{array}{l}\text { Yang et al. } \\
(2020)\end{array}$ \\
\hline
\end{tabular}

a novel triage marker to supplement HR-HPV testing in patients with LSILs (Xie et al., 2017). Analyzing the levels of miR-205 can serve as a supplement to the screening of HR-HPVs, which can help determine which patients with LSILs will progress to HSILs.

Circulating miRNAs are attractive as biomarkers in cervical cancer because this eliminates the need to take solid tissue samples, simplifying sample collection. In this regard, You et al. analyzed three plasma miRNAs (miR-127, miR-205, and miR-218) for cervical cancer detection. The results showed that miR-205 had a higher predictive value with an AUC of 0.843 , a sensitivity of $72.00 \%$, and a specificity of $82.35 \%$ (You et al., 2015). Comparing these results with those obtained by Xie et al., it is likely that miR-205 could serve as a biomarker both in plasma and in samples from cervical tissue, although further research would be necessary to examine the levels of miR-205 in both sample types.

In another study, Farzanehpour et al. monitored the levels of miR-9, miR-192, and miR-205 in serum and tissue of cervical cancer and LSIL patients infected by HPV in comparison with normal tissue showing an increased expression level of miR-192 in tumor and L-SIL tissues, concluding that miR-192 can be used as a potential biomarker for the early detection of CC (Farzanehpour et al., 2019).

Finally, several research groups focused in establishing a miRNA profile for the detection of cervical cancer. For example, Jia et al. described a panel of 5 serum miRNAs (miR-21, miR-29a, miR-25, miR-200a, and miR-486-5p) as a cervical cancer biomarker. The ROC curves indicated that this panel may constitute a useful fingerprint test for early diagnosis. Interestingly, miR-29a and miR-200a may indicate tumor histological grade and progression stage (Jia et al., 2015).

\section{DISCUSSION}

The impact of miRNAs in cancer has been widely studied because of their capacity to influence many tumorigenic processes, such as sustained proliferative capacity, apoptosis resistance, invasion and metastasis induction and increased angiogenesis. Thus, several studies have focused on the expression profile of
miRNAs in different types of cancer and their functions in the tumorigenic process.

In this review, we highlighted the expression and function of four extensively studied miRNAs. Mainly, miR-21 was found upregulated in HPV infection and through regulation of several target genes is capable of enhancing progression to cervical cancer. Because of the well-established overexpression in cervical tumor tissue, miR-21 is described as a good diagnostic and prognostic marker. Also, miR-9a has been found upregulated in SCC associated with EMT through regulation of TWIST1 and $\mathrm{CDH} 1$ contributing to invasive CC development. In the case of miR-34a and miR-29, they are both downregulated in cervical carcinogenesis and are well known for their tumor suppressor functions. These miRNAs are associated with an ICC state through the regulation of genes involved in migration, invasion, and EMT (WNT1, SIRT1, and HSP47).

Due to the discovery of miRNA aberrant expression associated with cervical cancer, the new molecular mechanism of cervical tumorigenesis has emerged providing opportunities for miRNAs become useful for clinical applications. Accordingly, it is important to categorize the expression and the function of miRNAs in the different stages that lead to cervical cancer (Figure 1); from the infection with HR-HPV, followed by subsequent LSIL to malignant transformation. Aberrant miRNA expression begins with HPV infection and despite most infections are spontaneously cleared in many patients, the HPV infection persists. Consequently, the expression profile of miRNAs continues changing throughout the cervical carcinogenesis development process. As mentioned above, the upregulation of miR-205 could be a marker for the diagnosis of $\mathrm{HPV}^{+}$intraepithelial lesions. The use of this miRNA could be more accurate than the determination of the HR-HPV oncoproteins in cervical tissue. In invasive SCC the overexpression of $\mathrm{miR}-21$ and downregulation of miR-29 stands out in tumors compared to normal cervical tissue providing a molecular signature useful for cervical cancer diagnosis.

Most miRNAs possess some advantages that could turn them into ideal candidates as biomarkers for the diagnosis and prognosis of cervical cancer. For example, their stability, accessibility for measurement, specificity for the tissue or cell 
type and a putative capability to be more informative than other biomolecules. Although these advantages suggest a promising clinical implication of miRNA-based diagnosis the validation of miRNA as biomarkers has not been successful. This can be explained by many methodological challenges including sample collection, storage, extraction methods, quality controls, differences in methodology of the studies, the lack of standard methods for normalization, and the inability to discriminate among closely related miRNAs (Saliminejad et al., 2019). Besides the potential technical biases mentioned above, other critical variables that could have deep implications in the accurate interpretation of miRNA biomarker studies are related to the intrinsic variability, such as the heterogenicity of the tumor itself since miRNA expression pattern may fluctuate among different patients with the same type of cancer due to the individual variability such as race and gender, life-style and external factors, drugs, smoking habits, and other conditions (Tiberio et al., 2015).

Thus, considering all these limitations, every miRNA-based diagnosis study requires further steps of validation and a proper standardization of all analytical procedures, to control for all potential technical biases. Furthermore, deeper studies with a larger number of patients enrolled are required to discover a signature of specific and sensitivity miRNAs capable of discriminate between HPV-infection, dysplasia and cancer patients from healthy subjects.

In addition, the individual variability between different cervical cancer patients is not negligible and can influence miRNA application in clinical practice. Accordingly, miRNAs could be used as a complementary but not definitive diagnostic tool requiring the input from standard diagnosis practices such as Pap-smear cytology, histopathology, and HPV testing.

Besides diagnosis, some clinical trials have focused on the miRNA therapeutic efficacy in cervical cancer. Potential miRNA-based cervical cancer therapies focus on the

\section{REFERENCES}

Ali Syeda, Z., Langden, S. S. S., Munkhzul, C., Lee, M., and Song, S. J. (2020). Regulatory Mechanism of MicroRNA Expression in Cancer. Ijms 21, 1723. doi:10.3390/ijms21051723

Asangani, I. A., Rasheed, S. A. K., Nikolova, D. A., Leupold, J. H., Colburn, N. H., Post, S., et al. (2008). MicroRNA-21 (miR-21) post-transcriptionally Downregulates Tumor Suppressor Pdcd4 and Stimulates Invasion, Intravasation and Metastasis in Colorectal Cancer. Oncogene 27, 2128-2136. doi:10.1038/sj.onc. 1210856

Babion, I., Jaspers, A., VAN Splunter, A. P., VAN DER Hoorn, I. A. E., Wilting, S. M., and Steenbergen, R. D. M. (2020a). miR-9-5p Exerts a Dual Role in Cervical Cancer and Targets Transcription Factor TWIST1. Cells 9, 65. doi:10.3390/ cells 9010065

Babion, I., Miok, V., Jaspers, A., Huseinovic, A., Steenbergen, R. D. M., VAN Wieringen, W. N., et al. (2020b). Identification of Deregulated Pathways, Key Regulators, and Novel miRNA-mRNA Interactions in HPV-Mediated Transformation. Cancers 12, 700. doi:10.3390/cancers 12030700

Bansal, A., Singh, M. P., and Rai, B. (2016). Human Papillomavirus-Associated Cancers: A Growing Global Problem. Int. J. Appl. Basic Med. Res. 6, 84-89. doi:10.4103/2229-516X.179027

Bautista-Sánchez, D., Arriaga-Canon, C., Pedroza-Torres, A., De La RosaVelázquez, I. A., González-Barrios, R., Contreras-Espinosa, L., et al. (2020). delivery of miRNA mimics to restore the functions of tsmiRs or delivering antagomiRs to repress oncomiRs (Hanna et al., 2019). However, there are some challenges to overcome to develop miRNA-based therapies, such as degradation by nucleases upon addition into biological systems, poor delivery to target cells, off-target effects, and activation of immune responses (Segal and Slack, 2020). Despite the off-target effects that miRNA-based therapies may have, they are promising tools due to their many advantages compared with the highly unspecific and toxic therapies currently applied such as chemotherapy and radiotherapy. For example, because the anatomic location of cervical tumors, miRNAs can be easily delivered in the specific tumor site reducing the damage to normal cells.

The clinical implications of miRNA-based diagnostic and therapeutic strategies are necessary to reduce the mortality and successful management of cervical cancer. Thus, further studies are required to elucidate the role of miRNAs in cervical carcinogenesis and the mechanisms through which miRNAs regulate cellular process enhancing tumorigenesis. Those studies might provide suitable evidence of the role of miRNAs as diagnostic and prognosis biomarkers, as well as treatment molecules for cervical cancer.

\section{AUTHOR CONTRIBUTIONS}

EGB-V and MFP-yP contributed equally to literature research and figure artwork. LMA-S provided funding and critical review. Manuscript correction and original idea.

\section{FUNDING}

\section{CONACyT grant A1-S-9160.}

The Promising Role of miR-21 as a Cancer Biomarker and its Importance in RNA-Based Therapeutics. Mol. Ther. - Nucleic Acids 20, 409-420. doi:10.1016/ j.omtn.2020.03.003

Bayramoglu Tepe, N., Bozgeyik, E., Bozdag, Z., Balat, O., Ozcan, H. C., and Ugur, M. G. (2021). Identification of Autophagy-Associated miRNA Signature for the Cervical Squamous Cell Cancer and High-Grade Cervical Intraepithelial Lesions. Reprod. Biol. 21, 100536. doi:10.1016/j.repbio.2021.100536

Bedell, S. L., Goldstein, L. S., Goldstein, A. R., and Goldstein, A. T. (2020). Cervical Cancer Screening: Past, Present, and Future. Sex. Med. Rev. 8, 28-37. doi:10.1016/j.sxmr.2019.09.005

Berman, T. A., and Schiller, J. T. (2017). Human Papillomavirus in Cervical Cancer and Oropharyngeal Cancer: One Cause, Two Diseases. Cancer 123, 2219-2229. doi: $10.1002 /$ cncr.30588

Bhaskaran, M., and Mohan, M. (2014). MicroRNAs. Vet. Pathol. 51, 759-774. doi: $10.1177 / 0300985813502820$

Bhatla, N., and Singhal, S. (2020). Primary HPV Screening for Cervical Cancer. Best Pract. Res. Clin. Obstet. Gynaecol. 65, 98-108. doi:10.1016/ j.bpobgyn.2020.02.008

Bumrungthai, S., Ekalaksananan, T., Evans, M. F., Chopjitt, P., Tangsiriwatthana, T., Patarapadungkit, N., et al. (2015). Up-Regulation of miR-21 Is Associated with Cervicitis and Human Papillomavirus Infection in Cervical Tissues. PLOS ONE 10, e0127109. doi:10.1371/journal.pone.0127109

Burd, E. M. (2003). Human Papillomavirus and Cervical Cancer. Clin. Microbiol. Rev. 16, 1-17. doi:10.1128/cmr.16.1.1-17.2003 
Cafforio, P., Palmirotta, R., Lovero, D., Cicinelli, E., Cormio, G., Silvestris, E., et al. (2021). Liquid Biopsy in Cervical Cancer: Hopes and Pitfalls. Cancers 13, 3968. doi:10.3390/cancers13163968

Cai, Y., Yu, X., Hu, S., and Yu, J. (2009). A Brief Review on the Mechanisms of miRNA Regulation. Genomics, Proteomics \& Bioinformatics 7, 147-154. doi:10.1016/s1672-0229(08)60044-3

Castellsagué, X. (2008). Natural History and Epidemiology of HPV Infection and Cervical Cancer. Gynecol. Oncol. 110, S4-S7. doi:10.1016/j.ygyno.2008.07.045

Chandan, K., Gupta, M., and Sarwat, M. (2020). Role of Host and Pathogen-Derived MicroRNAs in Immune Regulation during Infectious and Inflammatory Diseases. Front. Immunol. 10, 3081. doi:10.3389/fimmu.2019.03081

Chen, X., Liu, J., Hao, X., Yan, L., and Gao, F. (2020a). The miR-424/miR-503 microRNA Cluster Prevents the Malignant Phenotype in Cervical Cancer Cells by Negatively Regulating CCND1. Mol. Ther. - Nucleic Acids. doi:10.1016/ j.omtn.2020.10.029

Chen, Y., Song, Y., Mi, Y., Jin, H., Cao, J., Li, H., et al. (2020b). microRNA-499a Promotes the Progression and Chemoresistance of Cervical Cancer Cells by Targeting SOX6. Apoptosis 25, 205-216. doi:10.1007/s10495-019-01588-y

Chendrimada, T. P., Gregory, R. I., Kumaraswamy, E., Norman, J., Cooch, N., Nishikura, K., et al. (2005). TRBP Recruits the Dicer Complex to Ago2 for microRNA Processing and Gene Silencing. Nature 436, 740-744. doi:10.1038/ nature 03868

Córdova-Rivas, S., Fraire-Soto, I., Mercado-Casas Torres, A., Servín-González, L., Granados-López, A., López-Hernández, Y., et al. (2019). 5p and 3p Strands of miR-34 Family Members Have Differential Effects in Cell Proliferation, Migration, and Invasion in Cervical Cancer Cells. Ijms 20, 545. doi:10.3390/ ijms 20030545

Dai, F., Chen, G., Wang, Y., Zhang, L., Long, Y., Yuan, M., et al. (2019). Identification of Candidate Biomarkers Correlated with the Diagnosis and Prognosis of Cervical Cancer via Integrated Bioinformatics Analysis. Ott 12, 4517-4532. doi:10.2147/ott.s199615

Ding, F., Liu, J., and Zhang, X. (2020). microRNA-375 Released from Extracellular Vesicles of Bone Marrow Mesenchymal Stem Cells Exerts Anti-oncogenic Effects against Cervical Cancer. Stem Cell Res Ther 11, 455. doi:10.1186/ s13287-020-01908-z

Farzanehpour, M., Mozhgani, S.-H., Jalilvand, S., Faghihloo, E., Akhavan, S., Salimi, V., et al. (2019). Serum and Tissue miRNAs: Potential Biomarkers for the Diagnosis of Cervical Cancer. Virol. J. 16, 116. doi:10.1186/s12985-019-1220-y

Felekkis, K., Touvana, E., Stefanou, Ch., and Deltas, C. (2010). microRNAs: a Newly Described Class of Encoded Molecules that Play a Role in Health and Disease. Hippokratia 14, 236-240.

Fu, K., Zhang, L., Liu, R., Shi, Q., Li, X., and Wang, M. (2020). MiR-125 Inhibited Cervical Cancer Progression by Regulating VEGF and PI3K/AKT Signaling Pathway. World J. Surg. Onc 18, 115. doi:10.1186/s12957-020-01881-0

Gao, C., Zhou, C., Zhuang, J., Liu, L., Liu, C., Li, H., et al. (2018). MicroRNA Expression in Cervical Cancer: Novel Diagnostic and Prognostic Biomarkers. J. Cel. Biochem. 119, 7080-7090. doi:10.1002/jcb.27029

Girardi, E., López, P., and Pfeffer, S. (2018). On the Importance of Host MicroRNAs during Viral Infection. Front. Genet. 9, 439. doi:10.3389/ fgene.2018.00439

Gregory, R. I., Yan, K.-P., Amuthan, G., Chendrimada, T., Doratotaj, B., Cooch, N., et al. (2004). The Microprocessor Complex Mediates the Genesis of microRNAs. Nature 432, 235-240. doi:10.1038/nature03120

Guo, M., Zhao, X., Yuan, X., Jiang, J., and Li, P. (2017). MiR-let-7a Inhibits Cell Proliferation, Migration, and Invasion by Down-Regulating PKM2 in Cervical Cancer. Oncotarget 8, 28226-28236. doi:10.18632/oncotarget.15999

Ha, M., and Kim, V. N. (2014). Regulation of microRNA Biogenesis. Nat. Rev. Mol. Cell Biol 15, 509-524. doi:10.1038/nrm3838

Han, M. S., Lee, J. M., Kim, S. N., Kim, J. H., and Kim, H. S. (20182018). Human Papillomavirus 16 Oncoproteins Downregulate the Expression of miR-148a-3p, miR-190a-5p, and miR-199b-5p in Cervical Cancer. Biomed. Res. Int. 2018, 1942867. doi:10.1155/2018/1942867

Hanna, J., Hossain, G. S., and Kocerha, J. (2019). The Potential for microRNA Therapeutics and Clinical Research. Front. Genet. 10, 478. doi:10.3389/ fgene.2019.00478

Harden, M. E., and Munger, K. (2017). Human Papillomavirus Molecular Biology. Mutat. Research/Reviews Mutat. Res. 772, 3-12. doi:10.1016/j.mrrev.2016.07.002
He, L., and Hannon, G. J. (2004). MicroRNAs: Small RNAs with a Big Role in Gene Regulation. Nat. Rev. Genet. 5, 522-531. doi:10.1038/nrg1379

Huang, J., Ni, S., and Tang, R. (2020). A Functional Polymorphism in the Promoter of miR-17-92 Is Associated with a Reduced Risk of Cervical Squamous Cell Carcinoma. Reprod. Sci. 27, 87-92. doi:10.1007/s43032-019-00007-6

Hull, R., Mbele, M., Makhafola, T., Hicks, C., Wang, S. M., Reis, R., et al. (2020). Cervical Cancer in Low and Middle-income C-ountries (Review). Oncol. Lett. 20, 2058-2074. doi:10.3892/ol.2020.11754

Hussein, M., and Magdy, R. (2021). MicroRNAs in central Nervous System Disorders: Current Advances in Pathogenesis and Treatment. Egypt. J. Neurol. Psychiatry Neurosurg. 57, 36. doi:10.1186/s41983-021-00289-1

Hussen, B. M., Hidayat, H. J., Salihi, A., Sabir, D. K., Taheri, M., and Ghafouri-Fard, S. (2021). MicroRNA: A Signature for Cancer Progression. Biomed. Pharmacother. 138, 111528. doi:10.1016/j.biopha.2021.111528

Jia, W., Wu, Y., Zhang, Q., Gao, G., Zhang, C., and Xiang, Y. (2015). Expression Profile of Circulating microRNAs as a Promising Fingerprint for Cervical Cancer Diagnosis and Monitoring. Mol. Clin. Oncol. 3, 851-858. doi:10.3892/ mco. 2015.560

Jiang, Y., Hu, Z., Zuo, Z., Li, Y., Pu, F., Wang, B., et al. (2020). Identification of Circulating MicroRNAs as a Promising Diagnostic Biomarker for Cervical Intraepithelial Neoplasia and Early Cancer: A Meta-Analysis. Biomed. Res. Int. 2020, 4947381. doi:10.1155/2020/4947381

Kumarswamy, R., Volkmann, I., and Thum, T. (2011). Regulation and Function of miRNA-21 in Health and Disease. RNA Biol. 8, 706-713. doi:10.4161/ rna.8.5.16154

Lai, E. C. (2002). Micro RNAs Are Complementary to $3^{\prime}$ UTR Sequence Motifs that Mediate Negative post-transcriptional Regulation. Nat. Genet. 30, 363-364. doi:10.1038/ng865

Lee, J.-W., Choi, C. H., Choi, J.-J., Park, Y.-A., Kim, S.-J., Hwang, S. Y., et al. (2008). Altered MicroRNA Expression in Cervical Carcinomas. Clin. Cancer Res. 14, 2535-2542. doi:10.1158/1078-0432.ccr-07-1231

Lenkala, D., Lacroix, B., Gamazon, E. R., Geeleher, P., Im, H. K., and Huang, R. S. (2014). The Impact of microRNA Expression on Cellular Proliferation. Hum. Genet. 133, 931-938. doi:10.1007/s00439-014-1434-4

Li, B., Guo, X., Li, N., Chen, Q., Shen, J., Huang, X., et al. (2020). WNT1, a Target of miR-34a, Promotes Cervical Squamous Cell Carcinoma Proliferation and Invasion by Induction of an E-P Cadherin Switch via the WNT/ $\beta$-catenin Pathway. Cell Oncol. 43, 489-503. doi:10.1007/s13402020-00506-8

Li, B., Hu, Y., Ye, F., Li, Y., Lv, W., and Xie, X. (2010). Reduced miR-34a Expression in Normal Cervical Tissues and Cervical Lesions with High-Risk Human Papillomavirus Infection. Int. J. Gynecol. Cancer 20, 597-604. doi:10.1111/ igc.0b013e3181d 63170

Li, N., Cui, T., Guo, W., Wang, D., and Mao, L. (2019a). MiR-155-5p Accelerates the Metastasis of Cervical Cancer Cell via Targeting TP53INP1. Ott Volume 12, 3181-3196. doi:10.2147/ott.s193097

Li, N., Guo, X., Liu, L., Wang, L., and Cheng, R. (2019b). Molecular Mechanism of miR-204 Regulates Proliferation, Apoptosis and Autophagy of Cervical Cancer Cells by Targeting ATF2. Artif. Cell Nanomedicine, Biotechnol. 47, 2529-2535. doi:10.1080/21691401.2019.1628038

Li, T., Zhou, W., Li, Y., Gan, Y., Peng, Y., Xiao, Q., et al. (2019c). MiR-4524b-5p/ WTX/ $\beta$-catenin axis Functions as a Regulator of Metastasis in Cervical Cancer. PLOS ONE 14, e0214822. doi:10.1371/journal.pone.0214822

Li, Y., and Xu, C. (2017). "Human Papillomavirus-Related Cancers," in Infectious Agents Associated Cancers: Epidemiology and Molecular Biology. Editors Q. CAI, Z. YUAN, and K. LAN (Singapore: Springer). doi:10.1007/978-98110-5765-6_3

Liu, J., and Ni, S. (2018). Association between Genetic Polymorphisms in the Promoters of Let-7 and Risk of Cervical Squamous Cell Carcinoma. Gene 642, 256-260. doi:10.1016/j.gene.2017.11.038

Liu, M., Wang, W., Chen, H., Lu, Y., Yuan, D., Deng, Y., et al. (2020). miR-9, miR21, miR-27b, and miR-34a Expression in HPV16/58/52-Infected Cervical Cancer. Biomed. Res. Int. 2020, 2474235. doi:10.1155/2020/2474235

López, J. A., and Alvarez-Salas, L. M. (2011). Differential Effects of miR-34c-3p and miR-34c-5p on SiHa Cells Proliferation Apoptosis, Migration and Invasion. Biochem. Biophysical Res. Commun. 409, 513-519. doi:10.1016/ j.bbrc.2011.05.036 
Lui, W.-O., Pourmand, N., Patterson, B. K., and Fire, A. (2007). Patterns of Known and Novel Small RNAs in Human Cervical Cancer. Cancer Res. 67, 6031-6043. doi:10.1158/0008-5472.can-06-0561

Mens, M. M. J., and Ghanbari, M. (2018). Cell Cycle Regulation of Stem Cells by MicroRNAs. Stem Cell Rev Rep 14, 309-322. doi:10.1007/s12015-018-9808-y

Moody, C. A., and Laimins, L. A. (2010). Human Papillomavirus Oncoproteins: Pathways to Transformation. Nat. Rev. Cancer 10, 550-560. doi:10.1038/ nrc2886

Morgan, E. L., Patterson, M. R., Ryder, E. L., Lee, S. Y., Wasson, C. W., Harper, K. L., et al. (2020). MicroRNA-18a Targeting of the STK4/MST1 Tumour Suppressor Is Necessary for Transformation in HPV Positive Cervical Cancer. PLoS Pathog. 16, e1008624. doi:10.1371/journal.ppat.1008624

Mou, Z., Xu, X., Dong, M., and Xu, J. (2016). MicroRNA-148b Acts as a Tumor Suppressor in Cervical Cancer by Inducing G1/S-phase Cell Cycle Arrest and Apoptosis in a Caspase-3-dependent Manner. Med. Sci. Monit. 22, 2809-2815. doi: $10.12659 / \mathrm{msm} .896862$

Muralidhar, B., Winder, D., Murray, M., Palmer, R., Barbosa-Morais, N., Saini, H., et al. (2011). Functional Evidence that Drosha Overexpression in Cervical Squamous Cell Carcinoma Affects Cell Phenotype and microRNA Profiles. J. Pathol. 224, 496-507. doi:10.1002/path.2898

Nan, P., Niu, Y., Wang, X., and Li, Q. (2019). MiR-29a Function as Tumor Suppressor in Cervical Cancer by Targeting SIRT1 and Predict Patient Prognosis. Ott 12, 6917-6925. doi:10.2147/ott.s218043

Navarro, F., and Lieberman, J. (2015). miR-34 and P53: New Insights into a Complex Functional Relationship. PLOS ONE 10, e0132767. doi:10.1371/ journal.pone. 0132767

Norouzi, S., Farhadi, A., Farzadfard, E., Akbarzade-Jahromi, M., Ahmadzadeh, N., Nasiri, M., et al. (2021). MicroRNAs Expression Changes Coincide with Low or High Grade of Squamous Intraepithelial Lesion Infected by HPV-16. Gene Rep. 23, 101186. doi:10.1016/j.genrep.2021.101186

Nowek, K., Wiemer, E. A. C., and Jongen-Lavrencic, M. (2018). The Versatile Nature of miR-9/9* in Human Cancer. Oncotarget 9, 20838-20854. doi:10.18632/oncotarget.24889

Nunvar, J., Pagacova, L., Vojtechova, Z., Azevedo, N. T. D. D., Smahelova, J., Salakova, M., et al. (2021). Lack of Conserved miRNA Deregulation in HPVInduced Squamous Cell Carcinomas. Biomolecules 11, 764. doi:10.3390/ biom1 1050764

Okunade, K. S. (2020). Human Papillomavirus and Cervical Cancer. J. Obstet. Gynaecol. 40, 602-608. doi:10.1080/01443615.2019.1634030

Palmirotta, R., Lovero, D., Cafforio, P., Felici, C., Mannavola, F., Pellè, E., et al. (2018). Liquid Biopsy of Cancer: a Multimodal Diagnostic Tool in Clinical Oncology. Ther. Adv. Med. Oncol. 10, 1758835918794630. doi:10.1177/ 1758835918794630

Pardini, B., De Maria, D., Francavilla, A., Di Gaetano, C., Ronco, G., and Naccarati, A. (2018). MicroRNAs as Markers of Progression in Cervical Cancer: a Systematic Review. BMC Cancer 18, 696. doi:10.1186/s12885018-4590-4

Park, S., Eom, K., Kim, J., Bang, H., Wang, H.-Y., Ahn, S., et al. (2017). MiR-9, miR21, and miR-155 as Potential Biomarkers for HPV Positive and Negative Cervical Cancer. BMC Cancer 17, 658. doi:10.1186/s12885-017-3642-5

Peng, Y., and Croce, C. M. (2016). The Role of MicroRNAs in Human Cancer. Sig Transduct Target. Ther. 1, 15004. doi:10.1038/sigtrans.2015.4

Qi, Y., Lai, Y.-L., Shen, P.-C., Chen, F.-H., Lin, L.-J., Wu, H.-H., et al. (2020). Identification and Validation of a miRNA-Based Prognostic Signature for Cervical Cancer through an Integrated Bioinformatics Approach. Sci. Rep. 10, 22270. doi:10.1038/s41598-020-79337-4

Ryndock, E. J., and Meyers, C. (2014). A Risk for Non-sexual Transmission of Human Papillomavirus? Expert Rev. Anti-infective Ther. 12, 1165-1170. doi:10.1586/14787210.2014.959497

Saliminejad, K., Khorram Khorshid, H. R., and Ghaffari, S. H. (2019). Why Have microRNA Biomarkers Not Been Translated from Bench to Clinic? Future Oncol. 15, 801-803. doi:10.2217/fon-2018-0812

Salvi, V., Gianello, V., Tiberio, L., Sozzani, S., and Bosisio, D. (2019). Cytokine Targeting by miRNAs in Autoimmune Diseases. Front. Immunol. 10, 15. doi:10.3389/fimmu.2019.00015

Sara, Z., Amir, S., Seyed Masoud, H., Marjan, R.-F., and Abolfazl, A. (2019). Deregulation of miR-21 and miR-29a in Cervical Cancer Related to HPV Infection. MicroRNA 8, 110-115.
Sara, Z., Seyed Masoud, H., and Amir, S. (2020). miR-21 and miR29-A: Potential Molecular Biomarkers for HPV Genotypes and Cervical Cancer Detection. MicroRNA 9, 271-275.

Segal, M., and Slack, F. J. (2020). Challenges Identifying Efficacious miRNA Therapeutics for Cancer. Expert Opin. Drug Discov. 15, 987-991. doi:10.1080/17460441.2020.1765770

Servín-González, L., Granados-López, A., and López, J. (2015). Families of microRNAs Expressed in Clusters Regulate Cell Signaling in Cervical Cancer. Ijms 16, 12773-12790. doi:10.3390/ijms160612773

Shen, S., Zhang, S., Liu, P., Wang, J., and DU, H. (2020). Potential Role of microRNAs in the Treatment and Diagnosis of Cervical Cancer. Cancer Genet. 248-249, 25-30. doi:10.1016/j.cancergen.2020.09.003

Sun, J., Ji, J., Huo, G., Song, Q., and Zhang, X. (2015). miR-182 Induces Cervical Cancer Cell Apoptosis through Inhibiting the Expression of DNMT3a. Int. J. Clin. Exp. Pathol. 8, 4755-4763.

Svoronos, A. A., Engelman, D. M., and Slack, F. J. (2016). OncomiR or Tumor Suppressor? the Duplicity of MicroRNAs in Cancer. Cancer Res. 76, 3666-3670. doi:10.1158/0008-5472.can-16-0359

Szymonowicz, K. A., and Chen, J. (2020). Biological and Clinical Aspects of HPVRelated Cancers. Cancer Biol. Med. 17, 864-878. doi:10.20892/j.issn.20953941.2020 .0370

Taghavipour, M., Sadoughi, F., Mirzaei, H., Yousefi, B., Moazzami, B., Chaichian, S., et al. (2020). Apoptotic Functions of microRNAs in Pathogenesis, Diagnosis, and Treatment of Endometriosis. Cell Biosci 10, 12. doi:10.1186/s13578-0200381-0

Tiberio, P., Callari, M., Angeloni, V., Daidone, M. G., and Appierto, V. (2015). Challenges in Using Circulating miRNAs as Cancer Biomarkers. Biomed. Res. Int. 2015, 731479. doi:10.1155/2015/731479

Tong, F., Andress, A., Tang, G., Liu, P., and Wang, X. (2020). Comprehensive Profiling of Extracellular RNA in HPV-Induced Cancers Using an Improved Pipeline for Small RNA-Seq Analysis. Sci. Rep. 10, 19450. doi:10.1038/s41598020-76623-z

Wang, A., Xu, Q., Sha, R., Bao, T., XI, X., and Guo, G. (2021a). MicroRNA-29a I-nhibits C-ell P-roliferation and A-rrests C-ell C-ycle by M-odulating P-16 M-ethylation in C-ervical C-ancer. Oncol. Lett. 21, 272. doi:10.3892/ ol.2021.12533

Wang, H., Zhang, D., Chen, Q., and Hong, Y. (2019). Plasma Expression of miRNA-21, $-214,-34 a$, and $-200 a$ in Patients with Persistent HPV Infection and Cervical Lesions. BMC Cancer. 19, 986. doi:10.1186/s12885-019-6066-6

Wang, X., Huang, X., and Zhang, Y. (2018). Involvement of Human Papillomaviruses in Cervical Cancer. Front. Microbiol. 9, 2896. doi:10.3389/ fmicb.2018.02896

Wang, X., Tang, S., LE, S.-Y., Lu, R., Rader, J. S., Meyers, C., et al. (2008). Aberrant Expression of Oncogenic and Tumor-Suppressive MicroRNAs in Cervical Cancer Is Required for Cancer Cell Growth. PLOS ONE 3, e2557. doi:10.1371/journal.pone.0002557

Wang, X., Wang, H.-K., Li, Y., Hafner, M., Banerjee, N. S., Tang, S., et al. (2014). microRNAs Are Biomarkers of Oncogenic Human Papillomavirus Infections. Proc. Natl. Acad. Sci. 111, 4262-4267. doi:10.1073/pnas.1401430111

Wang, X., Wang, H.-K., Mccoy, J. P., Banerjee, N. S., Rader, J. S., Broker, T. R., et al. (2009). Oncogenic HPV Infection Interrupts the Expression of TumorSuppressive miR-34a through Viral Oncoprotein E6. RNA 15, 637-647. doi:10.1261/rna.1442309

Wang, Y., Ru, J., Meng, X., Song, J., Jiang, Q., Li, S., et al. (2021b). Role of SNPs in the Biogenesis of Mature miRNAs. Biomed. Res. Int. 2021, 2403418. doi:10.1155/2021/2403418

Wang, Y., Dakhlallah, D., Moldovan, L., Anderson, T., Ezzie, M., Nana-Sinkam, S. P., et al. (2015). "Chapter 42 - Circulating MicroRNAs as Biomarkers," in MicroRNA in Regenerative Medicine. Editor C. K. SEN (Oxford: Academic Press).

Wei, Y. Q., Jiao, X. L., Zhang, S. Y., Xu, Y., Li, S., and Kong, B. H. (2019). MiR-9-5p Could Promote Angiogenesis and Radiosensitivity in Cervical Cancer by Targeting SOCS5. Eur. Rev. Med. Pharmacol. Sci. 23, 7314-7326. doi:10.26355/eurrev_201909_18837

Weng, S. L., Huang, K. Y., Weng, J. T., Hung, F. Y., Chang, T. H., and Lee, T. Y. (2017). Genome-wide Discovery of Viral microRNAs Based on Phylogenetic Analysis and Structural Evolution of Various Human Papillomavirus Subtypes. Brief Bioinform 19, 1102-1114. doi:10.1093/bib/bbx046 
WHO (2014). "Diagnosis and Treatment of Invasive Cervical Cancer," in Comprehensive Cervical Cancer Control: A Guide to Essential Practice. Editor W. H. O. 2nd edition.

WHO (2020). Globocan [Online]. Available at: https:/gco.iarc.fr/today/data/ factsheets/populations/900-world-fact-sheets.pdf (Accessed July 18, 2021).

Woodman, C. B. J., Collins, S. I., and Young, L. S. (2007). The Natural History of Cervical HPV Infection: Unresolved Issues. Nat. Rev. Cancer 7, 11-22. doi: $10.1038 / \mathrm{nrc} 2050$

Xia, Y.-F., Pei, G.-H., Wang, N., Che, Y.-C., Yu, F.-S., Yin, F.-F., et al. (2017). miR3156-3p Is Downregulated in HPV-Positive Cervical Cancer and Performs as a Tumor-Suppressive miRNA. Virol. J. 14, 20. doi:10.1186/s12985-017-0695-7

Xie, H., Norman, I., Hjerpe, A., Vladic, T., Larsson, C., Lui, W.-O., et al. (2017). Evaluation of microRNA-205 Expression as a Potential Triage Marker for Patients with Low-Grade Squamous Intraepithelial Lesions. Oncol. Lett. 13, 3586-3598. doi:10.3892/ol.2017.5909

Yamamoto, N., Kinoshita, T., Nohata, N., Yoshino, H., Itesako, T., Fujimura, L., et al. (2013). Tumor-suppressive microRNA-29a Inhibits Cancer Cell Migration and Invasion via Targeting HSP47 in Cervical Squamous Cell Carcinoma. Int. J. Oncol. 43, 1855-1863. doi:10.3892/ijo.2013.2145

Yang, J., Yan, Z., Wang, Y., Xu, J., Li, R., Li, C., et al. (2021). Association Study of Relationships of Polymorphisms in the miR-21, miR-26b, miR-221/222 and miR-126 Genes with Cervical Intraepithelial Neoplasia and Cervical Cancer. BMC Cancer 21, 997. doi:10.1186/s12885-021-08743-2

Yang, S., Wu, Y., Wang, S., Xu, P., Deng, Y., Wang, M., et al. (2020). HPV-related Methylation-based Reclassification and Risk Stratification of Cervical Cancer. Mol. Oncol. 14, 2124-2141. doi:10.1002/1878-0261.12709

Yao, S. (2016). MicroRNA Biogenesis and Their Functions in Regulating Stem Cell Potency and Differentiation. Biol. Proced. Online 18, 8. doi:10.1186/s12575016-0037-y

You, W., Wang, Y., and Zheng, J. (2015). Plasma miR-127 and miR-218 Might Serve as Potential Biomarkers for Cervical Cancer. Reprod. Sci. 22, 1037-1041. doi:10.1177/1933719115570902

Yuan, F., Sun, R., Chen, P., Liang, Y., Ni, S., Quan, Y., et al. (2016). Combined Analysis of Pri-miR-34b/c Rs4938723 and TP53 Arg72Pro with Cervical Cancer Risk. Tumor Biol. 37, 6267-6273. doi:10.1007/s13277-015-4467-y

Yuan, Y., Cai, X., Shen, F., and Ma, F. (2021). HPV post-infection Microenvironment and Cervical Cancer. Cancer Lett. 497, 243-254. doi:10.1016/j.canlet.2020.10.034

Zhang, R., Su, J., Xue, S. L., Yang, H., Ju, L. L., Ji, Y., et al. (2016). HPV E6/p53 Mediated Down-Regulation of miR-34a Inhibits Warburg Effect through Targeting LDHA in Cervical Cancer. Am. J. Cancer Res. 6, 312-320.
Zhang, Y., Liu, Y., Guo, X., Hu, Z., and Shi, H. (2020). Interfering human papillomavirus e6/e7 oncogenes in cervical cancer cells inhibits the angiogenesis of vascular endothelial cells via increasing mir-377 in cervical cancer cell-derived microvesicles. Ott 13, 4145-4155. doi:10.2147/ott.s239979

Zheng, M., Hou, L., Ma, Y., Zhou, L., Wang, F., Cheng, B., et al. (2019). Exosomal Let-7d-3p and miR-30d-5p as Diagnostic Biomarkers for Non-invasive Screening of Cervical Cancer and its Precursors. Mol. Cancer 18, 76. doi:10.1186/s12943-019-0999-x

Zheng, Z.-M., and Wang, X. (2011). Regulation of Cellular miRNA Expression by Human Papillomaviruses. Biochim. Biophys. Acta (Bba) - Gene Regul. Mech. 1809, 668-677. doi:10.1016/j.bbagrm.2011.05.005

Zhou, S.-S., Jin, J.-P., Wang, J.-Q., Zhang, Z.-G., Freedman, J. H., Zheng, Y., et al. (2018a). miRNAS in Cardiovascular Diseases: Potential Biomarkers, Therapeutic Targets and Challenges. Acta Pharmacol. Sin 39, 1073-1084. doi:10.1038/aps.2018.30

Zhou, W., Su, L., Duan, X., Chen, X., Hays, A., Upadhyayula, S., et al. (2018b). MicroRNA-21 Down-Regulates Inflammation and Inhibits Periodontitis. Mol. Immunol. 101, 608-614. doi:10.1016/j.molimm.2018.05.008

Zubillaga-Guerrero, M. I., Alarcón-Romero, Ldel. C., Illades-Aguiar, B., FloresAlfaro, E., Bermúdez-Morales, V. H., Deas, J., et al. (2015). MicroRNA miR-161 Regulates CCNE1 (Cyclin E1) Gene Expression in Human Cervical Cancer Cells. Int. J. Clin. Exp. Med. 8, 15999-16006.

Conflict of Interest: The authors declare that the research was conducted in the absence of any commercial or financial relationships that could be construed as a potential conflict of interest.

Publisher's Note: All claims expressed in this article are solely those of the authors and do not necessarily represent those of their affiliated organizations, or those of the publisher, the editors and the reviewers. Any product that may be evaluated in this article, or claim that may be made by its manufacturer, is not guaranteed or endorsed by the publisher.

Copyright (C) 2021 Bañuelos-Villegas, Pérez-yPérez and Alvarez-Salas. This is an open-access article distributed under the terms of the Creative Commons Attribution License (CC BY). The use, distribution or reproduction in other forums is permitted, provided the original author $(s)$ and the copyright owner(s) are credited and that the original publication in this journal is cited, in accordance with accepted academic practice. No use, distribution or reproduction is permitted which does not comply with these terms. 